\title{
Translating Evidence to Practice in Athletic Training
}

Cameron J. Powden, PhD, LAT, ATC

University of Indianapolis, Indianapolis, IN

Key Phrases

Evidence-Based, Literature Review, Knowledge-Translation Resources

\section{Correspondence}

Dr. Cameron Powden, University of Indianapolis, Health Pavilion, \#331, 1643 E Hanna Ave, Indianapolis, IN 46227.

E-mail: powdenc@uindy.edu

Twitter: @CamPowden

\section{Full Citation}

Powden CJ. Translating evidence to practice in athletic training. Clin Pract Athl Train. 2020;3(3): 1-3. https://doi.org/10.31622/2020/0003.3.1.

Submitted: October 21, 2020 Accepted: November 27, 2020

\section{EDITORIAL}

Evid idence and evidence-based practice (EBP) are buzzwords within the field of athletic training and healthcare. These words may create mixed feelings, as polarizing as politics, for athletic trainers. However, the unifying of these words into the fabric of athletic training has been symbolized with the integration of EBP as a core competency in the 2020 Standards for Accreditation of Professional Athletic Training Programs.' The framework for EBP is here to stay and it will be a driving force in the growth and recognition of the athletic training profession. ${ }^{2}$ The incorporation of EBP provides clinicians with the tools needed to search the literature, assess the quality, and integrate their clinical expertise in combination with patient values to interpret the appropriate clinical course of action.3,4 Furthermore, EBP can provide the base for quality improvement initiatives within athletic training to formalize the clinical expertise portion of EBP. Examples of the benefits of EBP are all around Us, signaling the need for all athletic trainers to embrace the practice.

The translation of EBP into clinical practice is not an easy one, however. Athletic trainers perceive that they lack the knowledge on how to implement EBP into clinical practice. ${ }^{5}$ Even when knowledge of EBP is increased, confidence in implementation methods decrease over time and resulted in the failed adoption of EBP concepts in clinical practice. ${ }^{5}$ To enhance the integration of the available literature into the clinical decisionmaking process there is a need to understand, breakdown, and overcome the barriers to EBP's implementation. Barriers related to time and the availability of EBP resources have been prevalent within the literature. ${ }^{6}$ These two barriers are most likely connected as busy clinicians' feelings that they may not have the physical time to commit to the reading, understanding, and interpretation of complex research articles would only be exacerbated by a lack of access to EBP resources that would reduce the investment needed to complete this process. ${ }^{6}$ Overall, this may signal the need for more processed and refined literature to reduce the perceived barrier of time and act as an approachable gateway into EBP habits. ${ }^{7}$

Systematic reviews and meta-analyses stand as the pinnacle of evidence and attempt to provide a refined view of the knowledge on a given topic. They do this well by completing many steps of the EBP process for a practicing clinician: search of literature, organization of multiple investigations, critical appraisal, and summary of evidence..$^{3,4}$ As such, systematic reviews have the potential to reduce the time needed to engage with the literature in order to develop the knowledge needed to inform clinical decisions. However, systematic reviews and meta-analyses often present barriers to the clinician as they may feel unapproachable due to complex contextualization of findings, statistical approaches, and a lack of actionable policy recommendations. ${ }^{8}$ You may be among the many clinicians that have identified a promising review 
only to realize that there was a lack of clinically relevant and actionable information beyond the conclusion statements. This situation leaves clinicians to press on into a review of other literature for the answers they seek. In turn, the EBP process is lengthened and may leave clinicians frustrated as they fall back on their clinical expertise with the failure of the EBP process.

To enhance the uptake of systematic reviews and meta-analyses, there is a need to reduce the barriers and enhance the clinical applicability of findings by enhancing knowledge-translation resources available to clinicians. Simplistically, these resources can take on the form of summaries that layout the systematic reviews take-home messages in layman's terms while adding value by evaluating the quality of the review, assessing the findings' applicability, and providing recommendations for adoption and translation. ${ }^{9}$ The Evidence-to-Practice Review (ETPR) manuscript type for Clinical Practice in Athletic Training provides an innovative format for knowledge-translation. ETPRs are short and digestible reviews of timely and relevant systematic reviews and meta-analyses with the focus on clinical applicability. The reviews provide a non-threatening, focused, and concise entryway into the evidence for the practicing clinician. Additionally, ETPRs focus on clinical translation of information as they are is designed to give actionable steps and organized resources for continued exploration, ultimately leading to enhancing knowledge and application into clinical practice.

The goal of research is to provide information that can directly impact clinical practice and inform practices such as quality improvement and practice-based research. Individual research investigations are often nuanced in ways that limit generalizability without the combination of multiple investigations. Meanwhile, systematic reviews often lack the detail needed to allow for easy translation and application of summary findings into clinical practice. Knowledgetranslation resources, like the ETRP, provide a bridge between individual investigations and systematic reviews. ETRP can provide summaries of the evidence in combination with specific protocol recommendations and details needed to inform practice-based research and quality improvement initiatives. Initiatives that are imperative as the profession of athletic training aims prove that we have fulfilled our social contract with the public of providing safe, effective, and timely health care for our patients. ${ }^{2}$ I encourage all to engage with knowledgetranslation resources, such as the ETPR, and to allow these innovative resources to facilitate the EBP process within their clinical practice.

\section{REFERENCES:}

1. Commission on Accreditation of Athletic Training Education. 2020 Standards for Accreditation of Professional Athletic Training Programs. https://caate.net/wpcontent/uploads/2018/09/2020Standards-for-Professional-Programscopyedited-clean.pdf. Accessed October 26, 2020.

2. McKeon PO, McKeon JMM, Geisler PR. Redefining professional knowledge in athletic training: whose knowledge is it anyway? Athl Train Ed J. 2017;1 2(2):95105. https://doi.org/10.4085/120295.

3. Sackett DL, Rosenberg WM, Gray JM, Haynes RB, Richardson WS. Evidence based medicine: what it is and what it isn't. In: British Medical Journal Publishing Group; 1996.

4. Steves R, Hootman JM. Evidence-based medicine: what is it and how does it apply to athletic training? J Athl Train. 2004;39(1):83.

5. Manspeaker SA, Hankemeier DA. Retained knowledge and use of evidence-based practice concepts. Athl Train Ed J. $2018 ; 13(3): 239-247$. https://doi.org/10.4085/1303239. 
6. McCarty CW, Hankemeier DA, Walter JM, Newton EJ, Van Lunen BL. Use of evidencebased practice among athletic training educators, clinicians, and students, part 2: attitudes, beliefs, accessibility, and barriers. J Athl Train. 2013;48(3):405-415. https://dx.doi.org/10.4085\%2F10626050-48.2.19.

7. Welch $C E$, Hankemeier DA, Wyant AL, Hays $D G$, Pitney WA, Van Lunen BL. Future directions of evidence-based practice in athletic training: perceived strategies to enhance the use of evidence-based practice. J Athl Train. 2014;49(2):234-244. https://doi.org/10.4085/1062-605048.2.19.

8. Chambers D, Wilson PM, Thompson CA, Hanbury A, Farley K, Light K. Maximizing the impact of systematic reviews in health care decision making: a systematic scoping review of knowledge-translation resources. The Milbank Quarterly. 2011 ;89(1):131-156. https://doi.org/10.1111/i.14680009.2011.00622.x.

9. Lavis JN. How can we support the use of systematic reviews in policymaking? PLoS Med. 2009;6(11):e 1000141. https://doi.org/10.1371/iournal.pmed.100 $\underline{0141 .}$. 